\title{
Galectin-1 is a diagnostic marker involved in thyroid cancer progression
}

\author{
VANESSA ARCOLIA $^{1}$, FABRICE JOURNE ${ }^{1,2}$, AURORE WATTIER ${ }^{1}$, EMMANUELLE LETEURTRE $^{3}$, \\ FLORENCE RENAUD $^{3}$, HANS-JOACHIM GABIUS ${ }^{4}$, MYRIAM REMMELINK ${ }^{5}$, \\ CHRISTINE DECAESTECKER ${ }^{6,8}$, ALEXANDRA RODRIGUEZ ${ }^{7}$, SÉBASTIEN BOUTRY $^{8}$, \\ SOPHIE LAURENT ${ }^{8,9}$ and SVEN SAUSSEZ ${ }^{1,7}$
}

\begin{abstract}
${ }^{1}$ Laboratory of Human Anatomy and Experimental Oncology, Faculty of Medicine and Pharmacy, University of Mons, Mons; ${ }^{2}$ Laboratory of Oncology and Experimental Surgery, Institut Jules Bordet, Université Libre de Bruxelles, Brussels, Belgium; ${ }^{3}$ Université Lille, Inserm, CHU Lille, UMR-S 1172 - JPARC - Jean-Pierre Aubert Research Center, F-59000 Lille, France; ${ }^{4}$ Institute of Physiological Chemistry, Faculty of Veterinary Medicine, Ludwig Maximilians University, D-80539 Munich, Germany; ${ }^{5}$ Department of Pathology, Hospital Erasme, Université Libre de Bruxelles; ${ }^{6}$ Laboratory of Image, Signal Processing and Acoustics (LISA), Ecole Polytechnique de Bruxelles, Université Libre de Bruxelles; ${ }^{7}$ Department of Oto-Rhino-Laryngology, CHU Saint-Pierre, Université Libre de Bruxelles, Brussels; ${ }^{8}$ Center for Microscopy and Molecular Imaging (CMMI), Gosselies; ${ }^{9}$ Department of General, Organic, Biomedical Chemistry, NMR and Molecular Imaging Laboratory, University of Mons, Mons, Belgium
\end{abstract}

Received January 24, 2017; Accepted April 27, 2017

DOI: 10.3892/ijo.2017.4065

\begin{abstract}
Fine-needle aspiration (FNA) is the most commonly used pre-operative technique for diagnosis of malignant thyroid tumor. However, many benign lesions, with indeterminate diagnosis following FNA, are referred to surgery. Based on multifunctionality of the endogenous galectin-1, we aimed to assess its status for early diagnosis of thyroid cancer. Immunohistochemistry for galectin-1 and -3 was performed on a clinical series of 69 cases of thyroid lesions. Galectin-1 expression was further examined in two additional tissue microarrays (TMA) composed of 66 follicular adenomas and 66 papillary carcinomas in comparison to galectin-3 and cytokeratin-19 (CK19). In addition, a knockdown of galectin-1 in papillary (TPC-1) and anaplastic (8505C) thyroid cancer cell lines was achieved by lentiviral transduction for in vitro experiments. A murine orthotopic thyroid cancer model was used to investigate tumor growth and metastatic ability. Immunohistochemical analyses of galectin- 1 and -3 in the series of 69 cases of thyroid lesions revealed that galectin-1 was completely absent in the epithelial compartment of all
\end{abstract}

Correspondence to: Dr Sven Saussez, Laboratory of Human Anatomy and Experimental Oncology, Faculty of Medicine and Pharmacy, University of Mons (UMons), Pentagone 2A, 6 Avenue du Champ de Mars, B-7000 Mons, Belgium

E-mail: sven.saussez@umons.ac.be

Key words: galectin-1, thyroid cancer, papillary, anaplastic, orthotopic mouse model benign thyroid lesions. Levels of both galectins significantly increased in the cytoplasmic compartment of malignant thyroid cells. Galectin-1 expression in the TMA yielded an excellent specificity (97\%), while galectin-3 and CK19 presented a higher sensitivity (>97\%) in discriminating benign from malignant thyroid lesions. In vitro experiments revealed that migration was negatively affected in TPC-1 galectin-1 knockdown (KD) cells, and that proliferation and invasion capacity of $8505 \mathrm{C}$ cells decreased after galectin-1 KD. Moreover, an orthotopic mouse model displayed a lower rate of tumor development with galectin-1 KD thyroid anaplastic cancer cells than in the control. Our findings support the introduction of galectin-1 as a reliable diagnostic marker for thyroid carcinomas. Its involvement in cell proliferation, migration, invasion and tumor growth also intimate functional involvement of galectin-1 in the progression of thyroid carcinoma, suggesting its potential as a therapeutic target.

\section{Introduction}

Thyroid cancer constitutes the most common endocrine malignancy increasingly diagnosed worldwide (1-4). Welldifferentiated thyroid carcinomas, including papillary and follicular carcinomas, accounts for approximately $95 \%$ of all thyroid tumors (5). Respective patients have an excellent prognosis, with $85-90 \%$ benefiting from early detection and treatment. In contrast, undifferentiated anaplastic thyroid carcinomas are rare and highly aggressive tumors. The prognosis of these patients is very poor with a mortality rate of nearly $100 \%$ (4-6).

The preoperative characterization of thyroid nodules is still a challenge for the clinicians. Nowadays, thyroid ultrasonography (USG) and thyroid fine needle aspiration (FNA) 
are the most commonly pre-operative techniques used for the diagnosis of malignant thyroid tumors. However, FNA is an invasive procedure that showed inconclusive biopsy results in $10-20 \%$ of all cases, when solely based on histopathological evaluation. Additional immunohistochemical markers are thus required for accurate and reliable diagnosis of thyroid lesions. To address this issue, attention has been given to galectin-3 and cytokeratin-19 as potential markers (7-17). However, both markers have some limitations, because significant expression was reported in few proportion of benign thyroid nodules (18-23), suggesting that galectin-3, an adhesion/growth-regulatory tissue lectin, and cytokeratin-19 are interesting but not completely reliable immunohistochemical markers to distinguish benign from malignant thyroid lesions. Thus, there is a need to identify novel biomarkers that could be used to separate benign from cancer thyroid nodules. Such biomarkers could also offer new insights into the biology of thyroid cancers, with potential for innovations of targeted therapies.

Following the traits of galectin-3, the emerging network concept for this class of multifunctional effectors working in the cell and extracellularly guides interest to further members of this family $(24,25)$. Several galectins can be expressed by tumors, as documented for colon and head and neck cancer as well as also in other types of diseases (26-28), with marked impact on cancer progression by itself and by functional cooperation between the proteins. Homodimeric galectin-1 is an apparent candidate for analysis, sharing counter-receptors with galectin-3, and exhibits a tumor-type-specific impact on progression (29-32). The expression of galectin-1 has been shown to be upregulated in thyroid carcinoma-derived cell lines (33-35), and our team has previously reported for the first time a high serum level of galectin-1 in patients diagnosed with a well-differentiated thyroid cancer (36).

In the present study, we compared the diagnostic value of the galectin-1 to galectin-3 and cytokeratin-19 using a panel of benign and malignant thyroid lesions in order to answer the question whether galectin-1 may be viewed as a biomarker for diagnosis of thyroid cancer. We also examined the implication of galectin-1 depletion on proliferation and invasion of papillary and anaplastic thyroid cancer cell lines as well as on tumor growth in an orthotopic nude mouse model.

\section{Materials and methods}

Clinical data. The immunohistochemical detection of galectin-1 and -3 was first studied in a clinical series of specimens of four healthy patients [gender: 2 male/2 female, median age (range): 34 years (23-54), 4 total thyroidectomies], 40 patients with benign thyroid lesions (10 colloid nodules, 16 follicular adenomas, 7 Hashimoto's thyroiditis and 7 Graves' disease), and 29 patients with malignant thyroid lesions (17 papillary carcinomas and 12 follicular variant of papillary carcinomas). For these 69 cases, the age range was 22-81 years with a median of 54; 9 patients were male and 60 were female ( 36 hemi-thyroidectomies and 33 total thyroidectomies). To extend this series, two tissue microarrays (TMA) composed of 66 follicular adenomas and 66 papillary carcinomas were processed accordingly (galectin-1, galectin-3 and cytokeratin-19). Written informed consent was obtained from all the patients to use the surgical specimens for scientific research. Approval for any experiments was obtained from the institutional ethics committee. The patient samples and clinical data were collected retrospectively from the records of the pathology departments of the CHU Erasme (Brussels, Belgium), the EpiCURA Center (Baudour, Belgium), the Saint Pieter's HospitalBordet Institute (Brussels, Belgium) and the Lille University Hospital (Lille, France) selected by two pathologists (Professor M. Remmelink and Professor E. Leteurtre), then analyzed semi-quantitatively (blind scoring) using a light microscope (Axiocam MRc5, Zeiss, Oberkochen, Germany). All samples were collected with written informed consent and the study was approved by the ethics committee of the University of Mons (Mons, Belgium) (OM 004).

Immunohistochemistry on tissue specimens and tissue microarrays. All tumor samples were routinely fixed for $24 \mathrm{~h}$ in $4 \%$ buffered formaldehyde, dehydrated and then embedded in paraffin. Immunohistochemistry was performed on $5 \mu \mathrm{m}$ sections that were mounted on silane-coated glass sides. Before starting the immunodetection, tissue sections were briefly exposed to microwave pre-treatment in a $0.01 \mathrm{M}$ citrate buffer ( $\mathrm{pH} \mathrm{6.2)} \mathrm{for} 7 \mathrm{~min}$ at $900 \mathrm{~W}$ and then for $10 \mathrm{~min}$ at $350 \mathrm{~W}$. The sections were then pretreated with $0.06 \%$ hydrogen peroxide solution $\left(\mathrm{H}_{2} \mathrm{O}_{2}\right)$ for 4 min to block endogenous peroxidase activity, rinsed in phosphate-buffered saline (PBS) and successively exposed for $5 \mathrm{~min}$ to solutions containing avidin $(0.1 \mathrm{mg} / \mathrm{ml} \mathrm{PBS})$ and biotin $(0.1 \mathrm{mg} / \mathrm{ml} \mathrm{PBS})$ to avoid false-positive staining reaction from endogenous biotin. After a washing step with PBS, the sections were incubated for 15 min with a solution of $0.5 \%$ casein in PBS and sequentially exposed at room temperature to solutions of i) specific primary antibody (1 h): Galectin-1 (polyclonal rabbit anti-human galectin-1: 1:100) $(29,37)$, Galectin-3 (polyclonal rabbit antihuman galectin-3: 1:200) (29,37), CK19 (monoclonal mouse anti-human cytokeratin 19: 1:50; M0772; Dako, Glostrup, Denmark); ii) corresponding biotinylated secondary antibody (30 min): polyclonal goat anti-rabbit/mouse IgG (1:50; BA-1000/BA-9200, Vector Laboratories, Burlingame, CA, USA); and iii) avidin-biotin-peroxidase complex (ABC Kit Vector Laboratories). The specificity of galectin-1 and -3 antibodies was validated by western blotting in different thyroid cancer cell lines (B-CPAP, FTC133C and 8505C cell lines derived from papillary, follicular and anaplastic thyroid carcinoma respectively) reporting immunoreactive band for galectin-1 at $14 \mathrm{kDa}$ and for galectin-3 at $26 \mathrm{kDa}$ (data not shown). The slides were thoroughly washed with PBS between incubation steps. Immunocomplexes were finally visualized by exposure to the chromogen diaminobenzidine (DAB, BioGenex, Fremont, CA, USA) in the presence of $\mathrm{H}_{2} \mathrm{O}_{2}$. After rinsing, the sections were counterstained with luxol fast blue and mounted with a synthetic medium. To exclude antigenindependent staining, the incubation step with primary antibodies was omitted from the protocol as negative controls. In all cases, these controls were negative (data not shown). Individual tissue specimens were given a score (0-6) by adding the percent of immunopositive cells (range 0-3: $0=0 \%$, $1=1-33 \%, 2=34-66 \%$, and $3=67-100 \%$ ) to the intensity score (range $0-3,0=$ no, $1=$ low, $2=$ moderate, and $3=$ high). 
Cell culture conditions. Two cell lines from human thyroid cancers were studied: TPC-1 derived from papillary carcinoma and $8505 \mathrm{C}$ derived from anaplastic carcinoma (kindly gifted by Professor C. Maenhaut, IRIBHM ULB, Brussels, Belgium). The HeLa cell line derived from a cervical carcinoma (kindly gifted by Dr J. Martial, ULg, Liège, Belgium) was used as the positive control of galectin-1 expression. The TPC-1 and 8505C cell lines were grown in RPMI-1640 (Lonza, Verviers, Belgium) supplemented with $10 \%$ fetal bovine serum (FBS, Lonza, Verviers, Belgium) and $1 \%$ penicillin/streptomycin (PAA Laboratories, Pasching, Austria). HeLa cells were cultured in Dulbecco's modified Eagle's medium (DMEM) supplemented with 10\% FBS and $1 \%$ penicillin/streptomycin. Cells were incubated at $37^{\circ} \mathrm{C}$ in a humidified $95 \%$ air $/ 5 \% \mathrm{CO}_{2}$ atmosphere. The culture medium was changed once every two days. For routine maintenance and experimental studies, cells were detached by incubation with accutase solution (PAA Laboratories), resuspended and counted using an electronic cell counter (model Z1 Coulter counter, Beckman Coulter, Fullerton, CA, USA) before plating.

Depletion of galectin-1. Galectin-1 knockdown (gal-1 KD) transfectant cells derived from TPC-1 and $8505 \mathrm{C}$, as well as matched control cells with normal galectin-1 expression, were generated in our laboratory. Knockdown of galectin-1 expression was achieved by using shRNA lentiviral particles targeting galectin-1 specific mRNA (sc-35441-v, Santa Cruz Biotechnology, Santa Cruz, CA, USA). Control cells were obtained by transduction with shRNA lentiviral particles encoding a scrambled shRNA sequence (gal-1 sc). TPC-1 and $8505 \mathrm{C}$ cells were processed according to the manufacturer's instructions. Stable clones were selected by addition of $2 \mu \mathrm{g} / \mathrm{ml}$ puromycin (InvivoGen, San Diego, CA, USA) to the culture medium, preliminary experiments showed that this concentration was toxic on non-transduced cells.

Immunofluorescence staining. Twelve-well culture plates containing sterile round glass coverslips were seeded at a density of $10^{4}-10^{5}$ cells/well and grown for four days. The cells were washed with PBS and fixed with 4\% paraformaldehyde (PFA) for $15 \mathrm{~min}$ at room temperature. The fixed cells were rinsed in PBS, permeabilized with $0.1 \%$ Triton $\mathrm{X}-100$ in PBS for 15 min and blocked with $0.05 \%$ casein in PBS (blocking solution) for $20 \mathrm{~min}$. The cells were incubated overnight with specific primary antibodies which were diluted in blocking solution. The following primary antibodies were used: galectin-1 (polyclonal rabbit anti-human galectin-1 at $1: 100,1 \mathrm{~h})(29,37)$ and matrix metalloproteinase 9 (MMP9) (polyclonal rabbit anti-MMP9 at 1:50, $1 \mathrm{~h}$; sc-10737, Santa Cruz Biotechnology). Then, the cells were washed with PBS containing $0.1 \%$ Triton $\mathrm{X}-100$ and incubated for $30 \mathrm{~min}$ with Alexa Fluor 488-conjugated anti-rabbit IgG (A-11008, Invitrogen, Gent, Belgium) diluted 1:50 in blocking solution. The cells were washed with PBS containing $0.1 \%$ Triton X-100 for $15 \mathrm{~min}$, rinsed with distilled water for $5 \mathrm{~min}$ and mounted with Vectashield Mounting Medium containing DAPI (Vector Laboratories), then examined by confocal microscopy using an Olympus FV1000D laser scanning inverted microscope (Olympus, Hamburg, Germany).
Western blotting. Cells were seeded in a T-75 culture flask and grown at $37^{\circ} \mathrm{C}$ and $5 \% \mathrm{CO}_{2}$ until confluence. The cells were washed with PBS and recovered on ice with a scraper in PBS. The pellet was resuspended in a detergent cocktail (M-PER Mammalian Extraction buffer) supplemented with protease (Halt protease inhibitor cocktail, Pierce, Rockford, IL, USA) and phosphatase inhibitors (Halt phosphatase inhibitor cocktail, Pierce). Protein concentrations were determined by the BCA Protein assay (Pierce) using bovine serum albumin as standard. Extracted proteins $(40 \mu \mathrm{g})$ were subjected to $10 \%$ SDS-PAGE and electrotransferred at $200 \mathrm{~mA}$ for $90 \mathrm{~min}$ on nitrocellulose membranes (iBlot ${ }^{\circledR}$ Dry Blotting system, Life Technologies-Invitrogen, Gent, Belgium). Immunodetection was performed using polyclonal rabbit anti-human galectin-1 (o/n, 1:1,000) $(29,37)$. Peroxidase-labeled anti-rabbit IgG antibody (1 h, 1:5,000; RPN4301, GE Healthcare, Diegem, Belgium) was used as secondary reagent. Peroxidase activity was visualized using the SuperSignal ${ }^{\circledR}$ West Pico Chemiluminescent Substrate (Pierce) following the manufacturer's instructions. Molecular weight markers were analyzed in parallel for internal calibration (PAGE Ruler Prestained Proteins, Thermo Fisher Scientific, Waltham, MA, USA). For semi-quantitative analysis, nitrocellulose membranes were reloaded with a mouse monoclonal anti- $\beta$-actin antibody (clone C4, 1:5,000; MAB1501, Millipore, Temecula, CA, USA) detected using a peroxidase-labeled anti-mouse IgG antibody $(1 / 5,000)$ (NA931, Amersham Pharmacia Biotech, Roosendaal, The Netherlands) and reagents of the Lumi-Light kit (Roche, Brussels, Belgium). Films were scanned (Image Reader, Raytest $^{\circledR}$, Straubenhardt, Germany) and the immunoreactive band intensities were quantified using the software AIDA ${ }^{\circledast}$ Image Analyser 3.45 (Raytest).

RNA extraction and real-time PCR. Cells were plated in T-75 culture flasks and cultured until confluence and lysed in RLT buffer supplemented with $\beta$-mercaptoethanol (RNeasy mini kit, Qiagen, Venlo, The Netherlands) at $4^{\circ} \mathrm{C}$, and then centrifuged with RNeasy spin column. After washing steps, RNA was collected in RNase-free water and subjected to DNase treatment as described by the manufacturer. RNA concentration was evaluated using a NanoDrop ${ }^{\mathrm{TM}} 1000$ spectrophotometer (Thermo Fisher Scientific, Wilmington, DE, USA). Then, expression profiles of galectin-1 and 18S RNAs were quantified by real-time PCR. cDNA was synthesised using a standard reverse transcription method (qScript cDNA SuperMix, Quanta Biosciences, Gaithersburg, MD, USA). Real-time PCR reactions were performed using the SYBR Green PCR Master Mix (Applied Biosystems, Foster City, CA, USA) and sequence-specific primer sets designed from PrimerBank (http://pga.mgh.harvard.edu/primerbank/) for galectin-1 (forward: 5'-TCGCCAGCAACCTGAATCTC-3', reverse: 5'-GCACGAAGCTCTTAGCGTCA-3', amplicon size: 81) and from Primer 3 (http://frodo.wi.mit.edu) for $18 \mathrm{~S}$ (forward: 5'-GCGGCGGAAAATAGCCTTTG-3', reverse: 5'-GATCACACGTTCCACCTCATC-3', amplicon size: 139) (Life Technologies, Gent, Belgium). The amplification was performed on a LightCycler ${ }^{\circledR} 480$ System (Roche Diagnostics $\mathrm{GmbH}$, Mannheim, Germany) using an initial activation step $\left(95^{\circ} \mathrm{C}\right.$ for $\left.10 \mathrm{~min}\right)$ followed by 40 cycles of amplification $\left(95^{\circ} \mathrm{C}\right.$ for $15 \mathrm{sec}$ and $60^{\circ} \mathrm{C}$ for $60 \mathrm{sec}$ ). Melting curves from $60^{\circ} \mathrm{C}$ to 
A

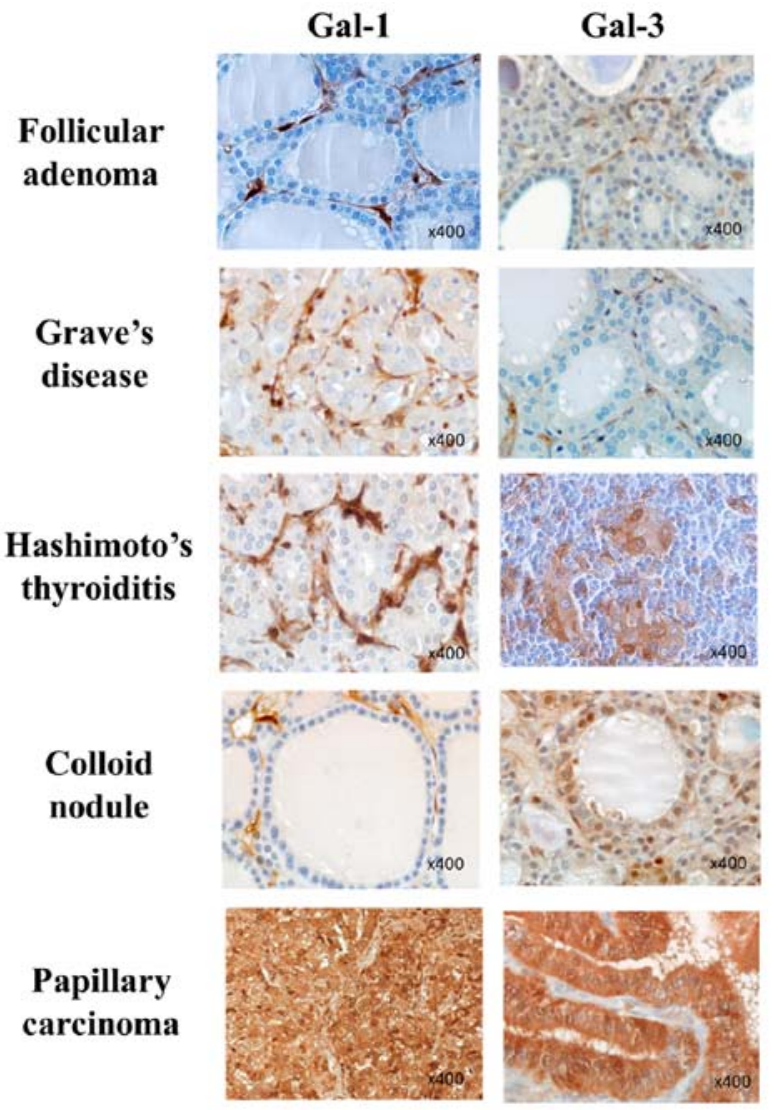

B

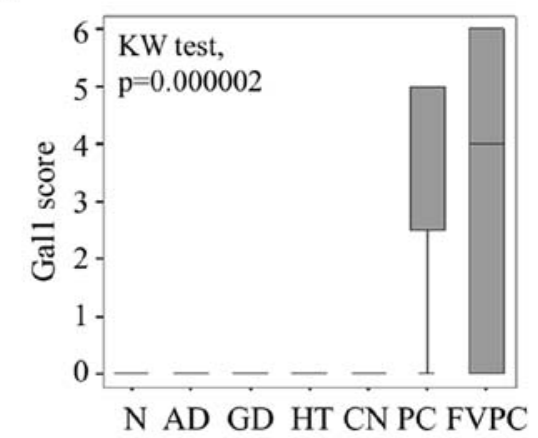

C

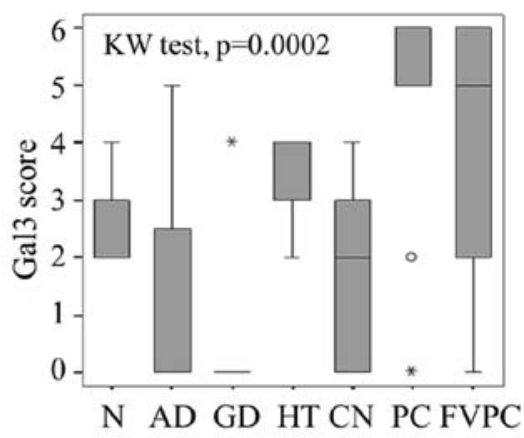

Figure 1. Evaluation of galectin-1 and galectin-3 expression in benign and malignant thyroid lesions. (A) Immunohistochemical expression of galectin-1 and galectin-3 in benign (follicular adenoma, Graves' disease, Hashimoto's thyroiditis, colloid nodule) and malignant (papillary carcinoma) thyroid lesions. Magnification x400. (B and C) Statistical analysis of galectin-1 and galectin-3 expression in a series of 69 cases of benign and malignant thyroid lesions ( $\mathrm{p}<0.001$, Kruskal-Wallis test). NT, normal tissue; AD, follicular adenomas; GD, Graves' diseases; HT, Hashimoto's thyroiditis; CN, colloid nodules; PC, papillary carcinomas; FVPC, follicular variant of papillary carcinomas. The immunostaining was semi-quantitatively assessed in the cytoplasmic compartment and scored from 0 to 6 by combining staining intensity $(0-3)$ and percentage of positivity $(0-3)$. Data are presented as box plots indicating the 1 st and the 3rd quartiles centered on medians (thick lines) with whiskers for the minimum and maximum non-outlier values.

$99^{\circ} \mathrm{C}$ were assessed to evaluate PCR specificity. A preliminary analysis demonstrated linear and similar amplification efficacies. Relative quantification was determined by normalizing the crossing threshold (CT) of galectin-1 with the CT of $18 \mathrm{~S}$ (loading control) using the $2^{-\Delta \mathrm{CT}}$ method (38).

Measurement of cell culture growth by cell counting. Transduced TPC-1 and $8505 \mathrm{C}$ cells were plated at a density of 15000 cells $/ \mathrm{cm}^{2}$ in 12 -well dishes. The next day, cell cultures were refed with fresh medium. Measurement of cell culture density was performed over 7 days after plating. Cells were detached by incubation with accutase solution (PAA Laboratories). After vigorous pipetting, the amounts of cells in suspension were determined using an electronic cell counter (model Z1 Coulter counter, Beckman Coulter).

Cell migration assay. Cell migration assay was performed using a wound healing assay (80209, Ibidi, Martinsried, Germany). The kit was used according to the manufacturer's instructions. Transfectants of the TPC-1 and 8505C lines were seeded at a density of $5 \times 10^{5}$ cells/well in a 6 -well plate cultured with RPMI-1640 complete medium and incubated for $24 \mathrm{~h}$. Culture inserts were removed creating a cell-free gap of $500 \mu \mathrm{m}$ and cells were washed with medium. Scratch wounds were observed under a microscope (Carl Zeiss
Axiovert 25C, Göttingen, Germany) and residual scratch distances were measured on images captured at 0, 4, 6 and $21 \mathrm{~h}$ after wounding.

Cell invasion assay. Cell invasiveness was assessed using a Boyden chamber assay consisting a 12-well plate (lower chambers) with cell culture inserts (upper chambers). The two chambers were separated by polycarbonate membrane (8- $\mu \mathrm{m}$ pore size) coated with an artificial extracellular matrix (ECM550, Chemicon Cell Invasion assay kit, Millipore, Billerica, MA, USA). The kit was used according to manufacturer's instructions. Gal-1 sc and gal-1 KD cells were seeded into the inserts $\left(5 \times 10^{5}\right.$ cells/insert) in serum-free medium (RPMI-1640) and complete medium (RPMI-1640, 10\% FBS) was added to the lower chamber. After $96 \mathrm{~h}$, non-invading cells on the upper side of the inserts were removed using a cotton-tipped swab and invading cells on the bottom side of the inserts were stained with crystal violet. Quantification was performed by counting the stained cells under an optical microscope in quadruplicate (Axiocam MRc5, Zeiss).

Mouse tumor models. Four-week-old male nude mice were used ( $n=18$, Charles River Laboratories, L'arbresle, France) and maintained under pathogen-free conditions for one week. The orthotopic transplantation was performed using $5 \times 10^{5}$ cells 


\section{Magnification}

$\mathbf{x 1 0 0}$ $\mathbf{x 2 0 0}$ $\mathrm{x} 400$

Follicular adenoma

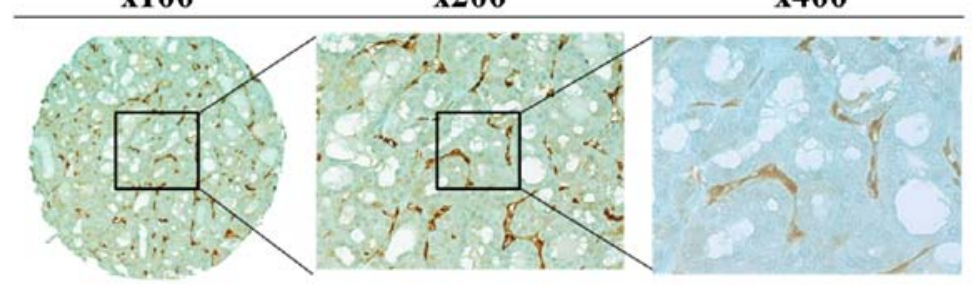

Papillary carcinoma

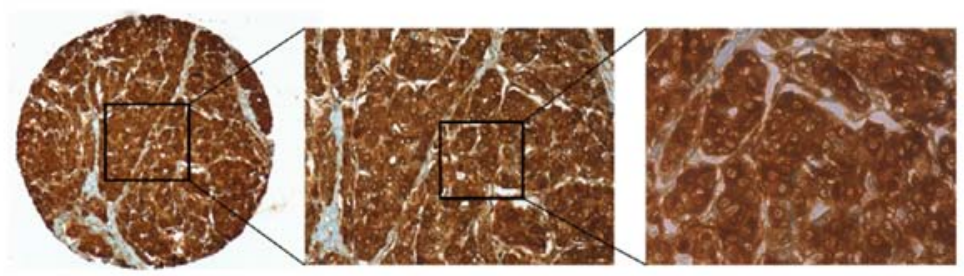

B

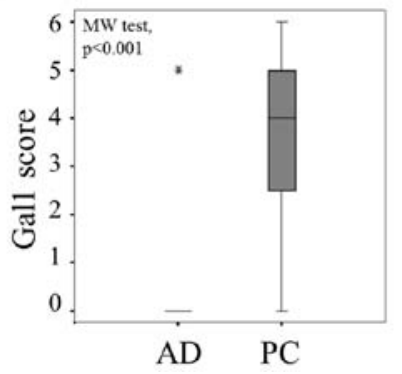

C

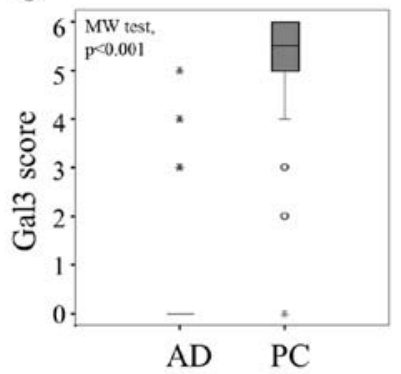

D

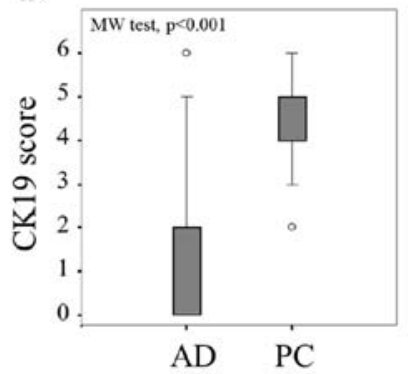

Figure 2. Comparison of immunopositivity for galectin-1, galectin-3 and cytokeratine-19 in follicular adenoma and papillary carcinoma. (A) Immunohistochemical evaluation of galectin-1 in tissue microarray (TMA) composed by follicular adenoma and papillary carcinoma. Magnification x100, x200 and x400. (B-D) Statistical analysis of galectin-1, galectin-3 and CK19 expression in a series of 66 cases of follicular adenomas (AD) and 66 cases of papillary carcinomas (PC) $(\mathrm{p}<0.001$, Mann-Whitney test). The immunostaining was semi-quantitatively assessed in the cytoplasmic compartment and scored from 0 to 6 by combining staining intensity (0-3) and percentage of positivity (0-3). Data are presented as box plots indicating the 1 st and the 3 rd quartiles centered on medians (thick lines) with whiskers for the minimum and maximum non-outlier values.

(8505C control and Gal-1 knockdown cells) suspended in Hank's balanced salt solution (HBSS) and, after cervicotomy under general anesthesia (ketamine-xylazine, $0.1 \mathrm{ml} / 10 \mathrm{~g}$, Sigma-Aldrich, St. Louis, MO, USA), injected into the left thyroid gland during microsurgery (Professor S. Saussez). Tumor growth was weekly followed by magnetic resonance imaging (MRI) using a 7T scanner (PharmaScan, Bruker, Ettlingen, Germany) equipped with a 40-mm volume coil and controlled with the ParaVision software. Animals were kept anesthetized with 1-1,5\% isoflurane delivered in oxygen. Their respiratory rate was monitored during the entire imaging session. A T2-weighted TurboRARE sequence was used: 19 axial slices of $0.75-\mathrm{mm}$ thickness with TR: $2000 \mathrm{msec}$, TE: $30 \mathrm{msec}, 0.100 \times 0.100 \mathrm{~mm}$ resolution, NEX: 20 . Tumor volumes were calculated from MR images using the VivoQuant software (InviCRO, Boston, MA, USA) by manually contouring the tumor on each slice. Mice were sacrificed 50 days after tumor cell inoculation or when mouse weight decreased to $20 \%$ under its initial weight (Nembutal, $0.1 \mathrm{ml} / 10 \mathrm{~g}$, Ceva, Brussels, Belgium). Tumors with adjacent tissues and lungs were collected and analyzed by hematoxylin/eosin coloration searching for tumor and metastases. All animal experiments were performed according to the institutional guidelines and approved by the ethics committee of the University of Mons (Mons, Belgium) (LVE-01-01).
Statistical analysis. The non-parametric Mann-Whitney U test as well as the Kruskal-Wallis test were used to investigate significant differences between the groups. Statistical evaluations included also Fisher's exact test. Cox regression and Kaplan-Meier method were used to perform survival analysis. A P-value $<0.05$ was considered statistically significant.

\section{Results}

Galectin-1, galectin-3 and cytokeratin-19 immunostaining profiles in benign and malignant thyroid lesions. The first aim of our study was to assess immunohistochemically presence of galectin-1 and -3 , in 40 benign thyroid lesions [including 16 adenomas (AD), 7 cases of Graves' disease (GD), 7 Hashimoto's thyroiditis (HT), 10 colloid nodules $(\mathrm{CN})]$ and in 29 malignant thyroid lesions [including 17 papillary carcinomas (PC) and 12 follicular variants of papillary carcinoma (FVPC)] and in four normal thyroid cases (N). The analysis of the cytoplasmic immunostaining revealed that both galectin-1 and galectin-3 were significantly higher expressed in cancer cells of malignant thyroid lesions (PC and FVPC) compared to epithelial cells in benign lesions (AD, GD, HT, CN) and in normal controls $(\mathrm{N})(\mathrm{p}=0.000002$ and $\mathrm{p}=0.0002$ for, respectively, galectin-1 and galectin-3; Kruskall-Wallis test). 
Table I. Diagnostic value of galectin-1, galectin-3 and CK19 in discrimination of malignant from benign thyroid tumors.

\begin{tabular}{lccccc}
\hline Proteins & Specificity (\%) & Sensitivity $(\%)$ & PPV $(\%)$ & NPV $(\%)$ & Fisher's exact test \\
\hline Galectin-1 & 97 & 80 & 96 & 83 & $\mathrm{p}<0.001$ \\
Galectin-3 & 83 & 97 & 85 & 96 & $\mathrm{p}<0.001$ \\
CK19 & 76 & 98 & 80 & 88 & $\mathrm{p}<0.001$ \\
\hline
\end{tabular}

PPV, positive predictive value; NPV, negative predictive value.

A

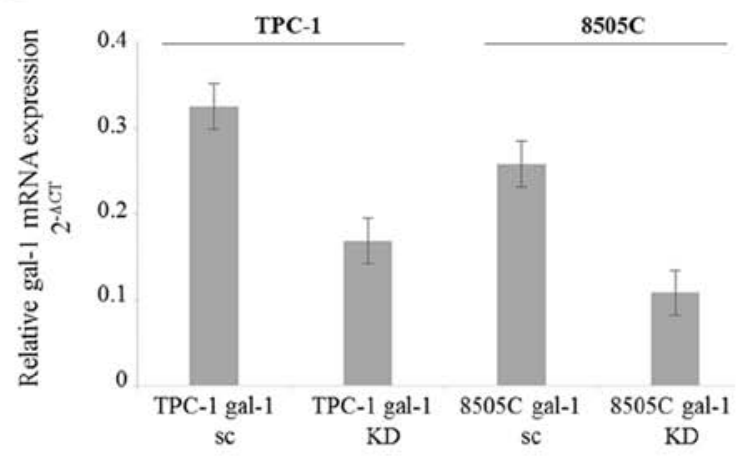

B

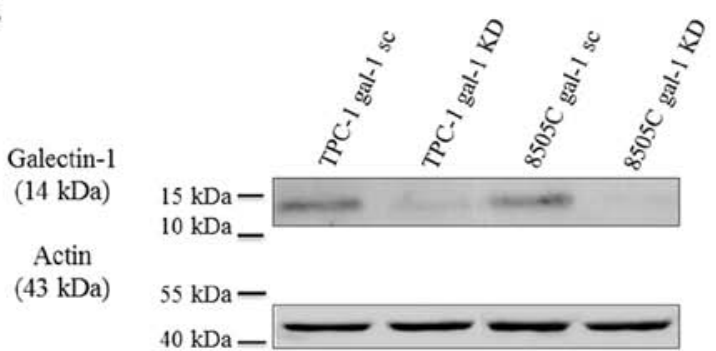

C
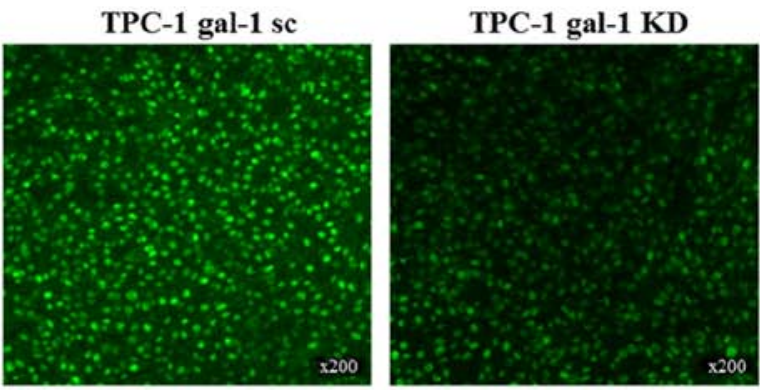

$8505 \mathrm{C}$ gal-1 KD

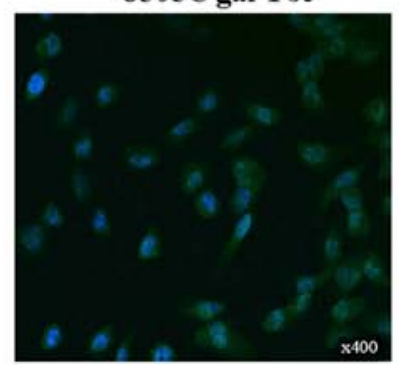

Figure 3. Demonstration of galectin-1 depletion in transfected thyroid cancer cell lines. (A) Real-time PCR, (B) western blotting and (C) immunofluorescence analysis demonstrating the downregulation of galectin-1 in TPC-1 and 8505C knockdown (gal-1 KD) cells compared to scrambled (gal-1 sc) ones. Real-time PCR data are presented as mean 2- $\Delta \mathrm{CT}$ values of replicates $\pm \mathrm{SD}$ (18S mRNA levels for normalization), western blotting shows an immunoreactive band for galectin-1 at $14 \mathrm{kDa}(\beta$-actin as loading control at $43 \mathrm{kDa})$, and immunofluorescence reveals a green cytoplasmic immunostaining in both cell lines; cell nuclei are stained by DAPI (blue staining) in $8505 \mathrm{C}$ cell line (magnification, $\mathrm{x} 200$ and $\mathrm{x} 400$ ).

Galectin-1 expression was completely absent in the epithelial compartment of all benign thyroid neoplasms (Fig. 1A and B), whereas a weak to moderate expression was found in benign samples for galectin-3 (Fig. 1A and C), suggesting that galectin-1 can be more reliable to distinguish malignant from benign lesions. Of note, considering the tumor microenvironment, stromal cells were also positive for galectin-1 and galectin-3, and both galectins were immunodetected in both benign and malignant lesions (Fig. 1A).

Extending these results by analysis of two series of tissue microarrays (TMA) composed of 66 follicular adenomas and 66 papillary carcinomas, a significantly higher expression of galectin-1, -3 and cytokeratin-19 was observed in papillary carcinomas (PC) than in follicular adenomas (AD) $(\mathrm{p}<0.001$, Mann-Whitney test) (Fig. 2), supporting that the diagnostic value of galectin-1 was as good as those of galectin-3 and cytokeratine-19. Of note, the cutoffs that we defined to separate negative/low versus positive immunostaining were $>0$ for galectin-1 and 3, and >2 for cytokeratin-19 (Fig. 2B-D). From crosstab analyses, the sensitivity, specificity and the positive/negative predictive values (PPV and NPV) were calculated for each marker (Table I). The data showed that galectin-1 exhibited an excellent specificity (97\%) to discriminate malignant from benign thyroid lesions with a very good PPV (96\%), while the highest performances for galectin-3 and cytokeratin-19 were rather seen for the sensitivity (>97\%) and the NPV (>96\%). Thus, analysis of galectin-1 could provide complementary information refining the conventional diagnostic markers.

Impact of galectin-1 depletion on papillary and anaplastic thyroid cancer cell proliferation, migration and invasion. To explore a galectin-1 functionality in thyroid cancer cells, we used a lentivirus-mediated shRNA to knock down galectin-1 expression in TPC-1 and $8505 \mathrm{C}$ cell lines derived from human papillary and anaplastic carcinoma, respectively. The baseline expression level of galectin-1 mRNA was slightly lower in $8505 \mathrm{C}$ wild-type cells than in TPC-1 wild-type cells. RT-qPCR, immunofluorescence and western blotting were realized to confirm the effective 
A

oh
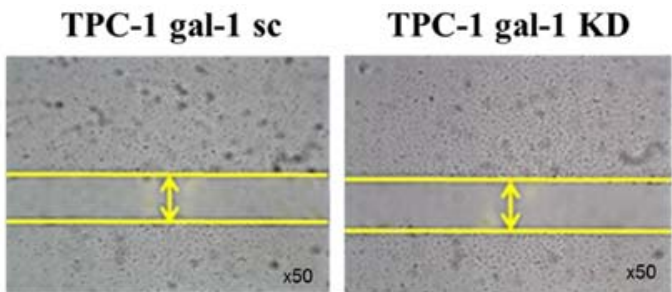

$4 \mathrm{~h}$

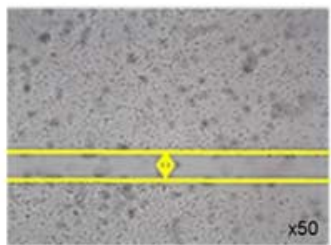

$6 \mathrm{~h}$
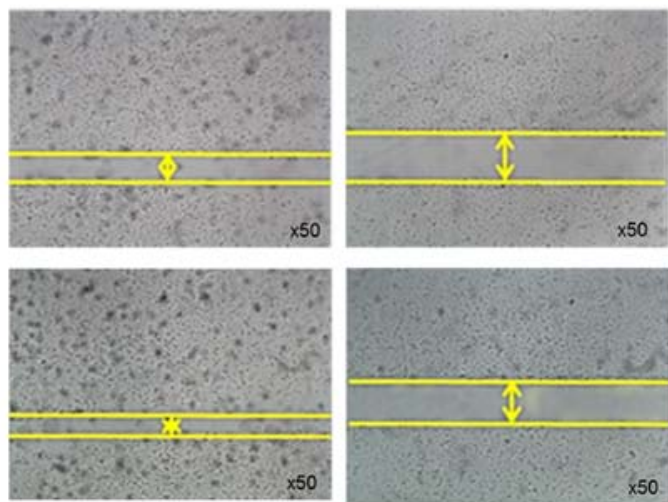

$21 \mathrm{~h}$
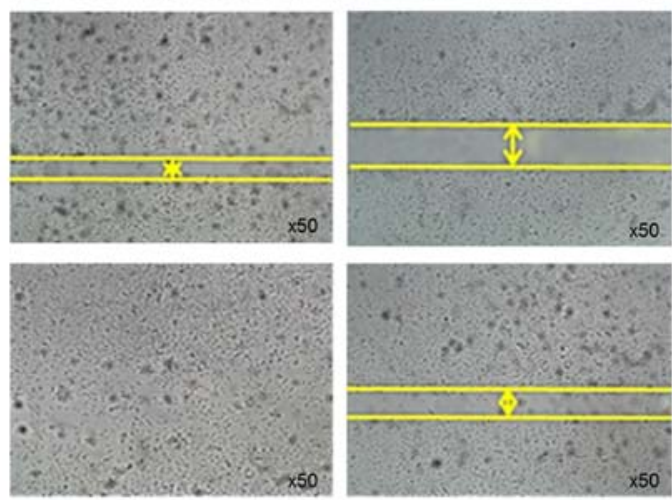

B

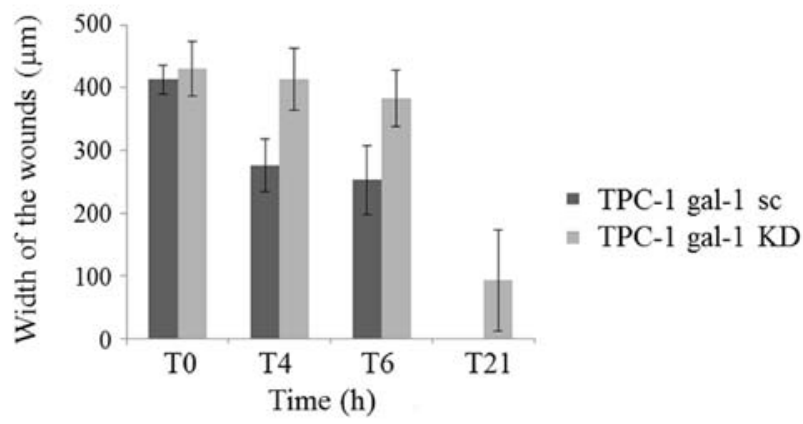

Figure 4. Effect of galectin-1 knockdown on TPC-1 cell migration. (A) Impact of galectin-1 depletion on the migration capacities of TPC-1 cells determined by Wound healing assay. Images of wounds $0,4,6$ and $21 \mathrm{~h}$ after wounding demonstrating the decrease of cell motility in TPC-1 galectin-1 knockdown cells (gal-1 KD) compared to scrambled cells (gal-1 sc). Magnification x50. (B) Quantification of the wounded width invaded at different time points (0, 4, 6 and $21 \mathrm{~h}$ ) by TPC-1 scrambled (gal-1 sc) and knockdown (gal-1 KD) cells. Data are mean values of triplicates \pm SD.

reduction (approximately 50\%) of galectin-1-specific mRNA and protein expression (Fig. 3).

First, we evaluated the effect of galectin-1 depletion on TPC-1 cells and observed no effect on cell proliferation and invasion (data not shown) but a significant reduction of cell migration. Monolayer wound healing assays were performed and the wound-closure distances have been measured comparing scrambled (TPC-1 gal-1 sc) and knockdown (TPC-1 gal-1 KD) TPC-1 cells (Fig. 4A). Quantification of cell motility over $21 \mathrm{~h}$ after scratching clearly showed that migration was significantly decreased in galectin-1 knockdown cells (Fig. 4A and B).

Then, we examined the effect of galectin-1 knockdown on $8505 \mathrm{C}$ anaplastic cell proliferation (cell counting over
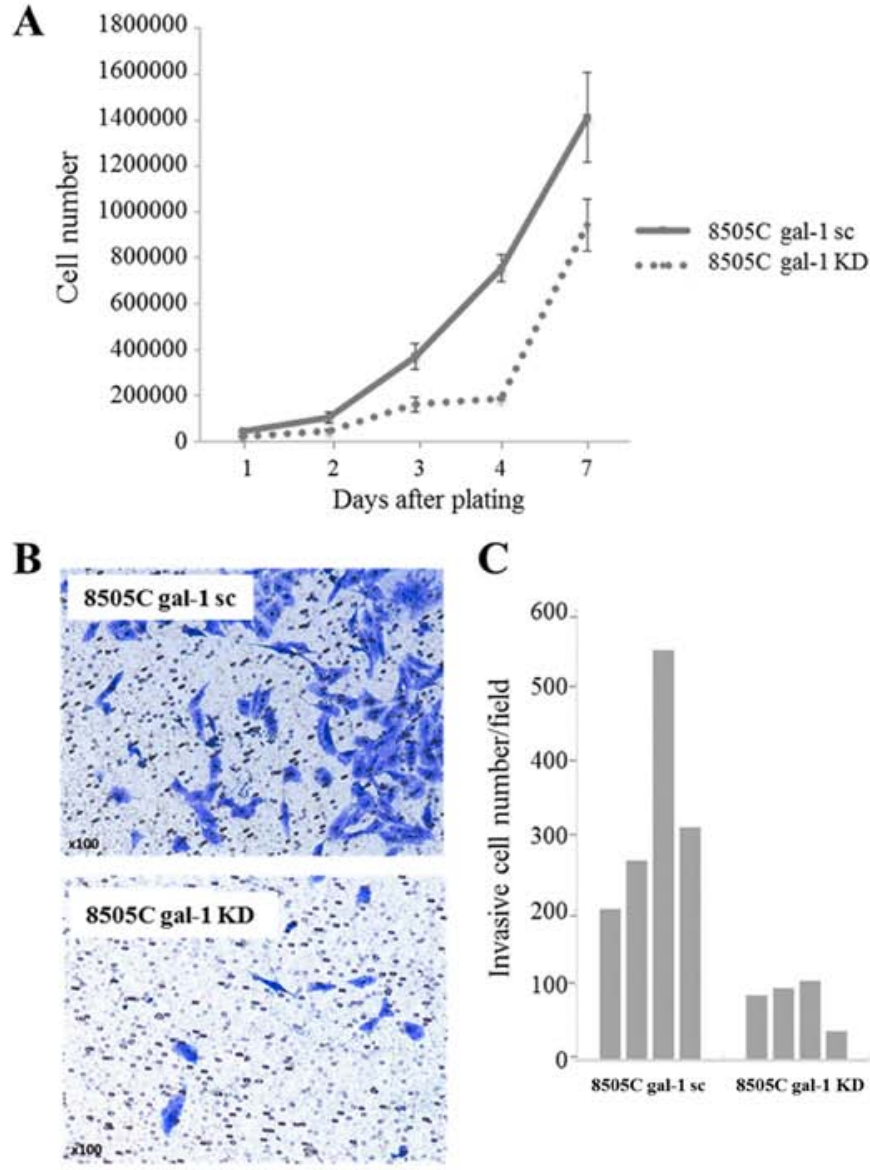

C

D

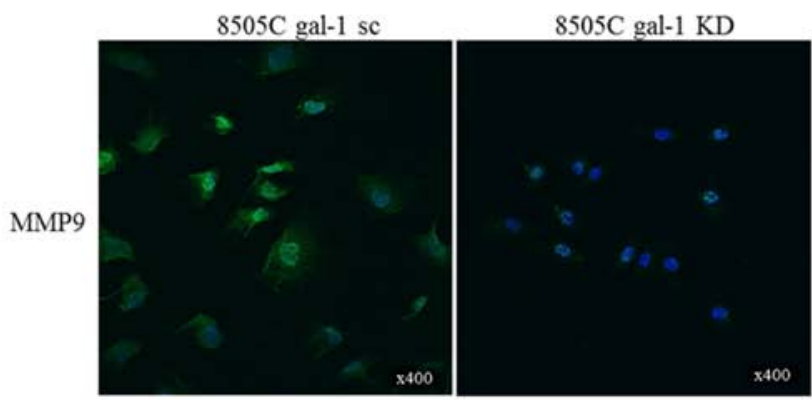

Figure 5. Impact of galectin-1 depletion on $8505 \mathrm{C}$ cell proliferation and invasion. (A) Effect of galectin-1 knockdown on $8505 \mathrm{C}$ cell growth determined by cell counting during 7 days. Data are mean values of triplicates \pm SD (B and C) Effect of galectin-1 depletion on the invasion capacities of 8505C cells determined by Boyden chamber assay. Inserts of Boyden chambers were seeded with scrambled (gal-1 sc) and knockdown (gal-1 KD) cells (four inserts per group). Invasive cells on the lower membrane surface were determined by cell counting after crystal violet staining (Magnification, $x 100$ ). Data are presented as individual values (quadruplicate for both $8505 \mathrm{C}$ gal-1 sc and $8505 \mathrm{C}$ gal-1 KD). (D) Detection of matrix metallopeptidase 9 (MMP9) expression by immunofluorescence in the cytoplasmic compartment of $8505 \mathrm{C}$ gal-1 sc and $8505 \mathrm{C}$ gal-1 KD cells; cell nuclei are stained by DAPI (blue staining). Magnification x400.

7 days). As illustrated in Fig. 5A, cell densities were significantly lower in galectin-1 knockdown cells (8505C gal-1 KD) than in scrambled cells $(8505 \mathrm{C}$ gal-1 sc), indicating that the depletion of galectin-1 could potently reduce the proliferation of thyroid cancer cells. Cell invasion assays in Boyden chambers were also performed to assess the impact of galectin-1 knockdown on $8505 \mathrm{C}$ cell invasiveness. In this case, the depletion of galectin-1 resulted in a significant inhibition of 
A
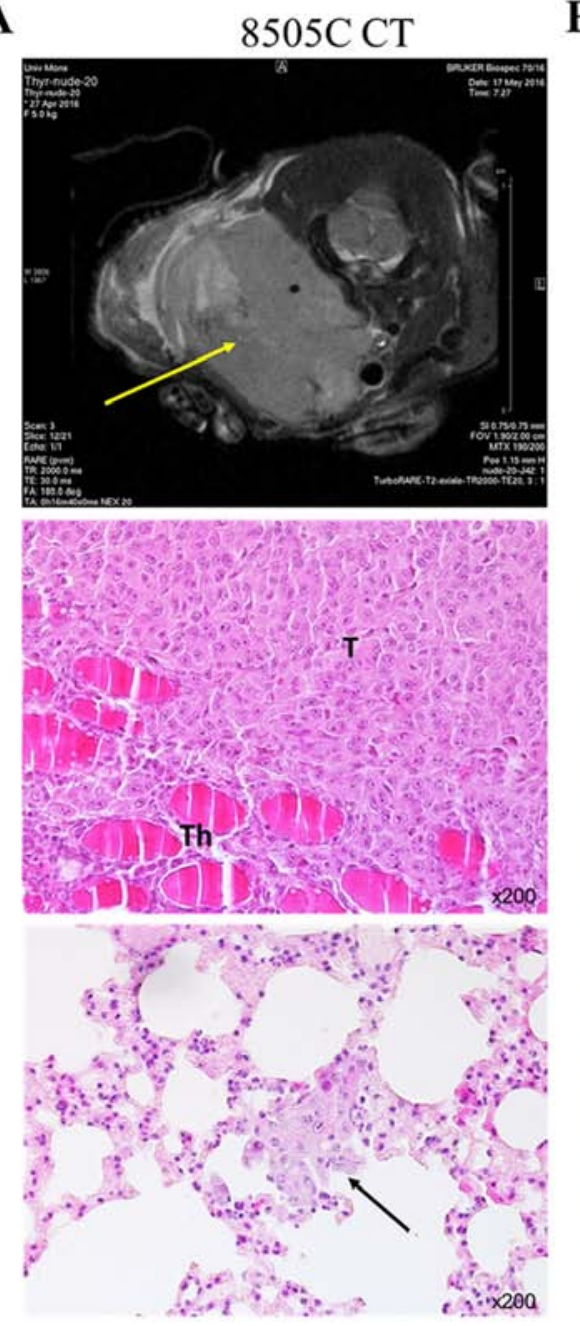

B
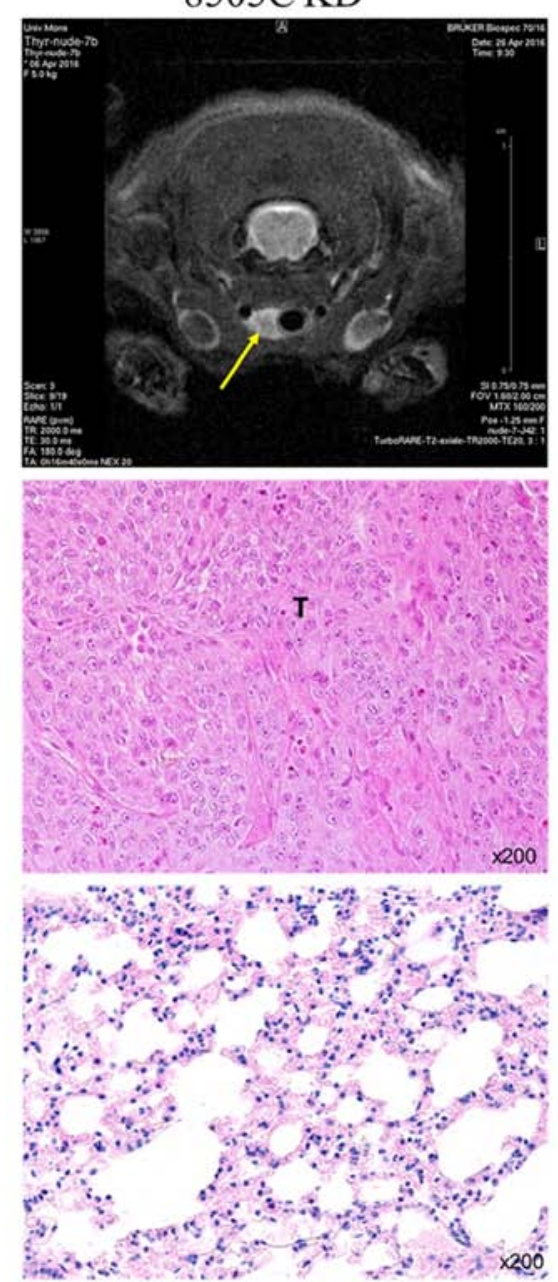

C

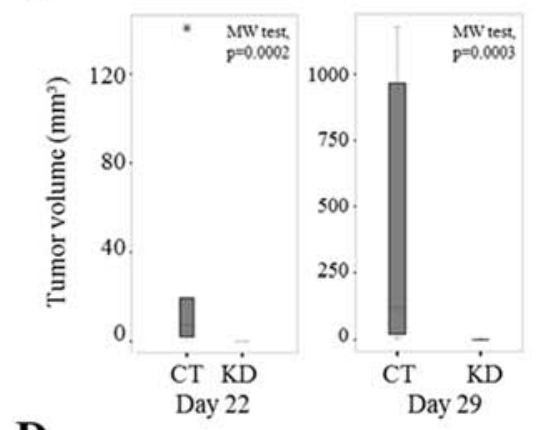

D

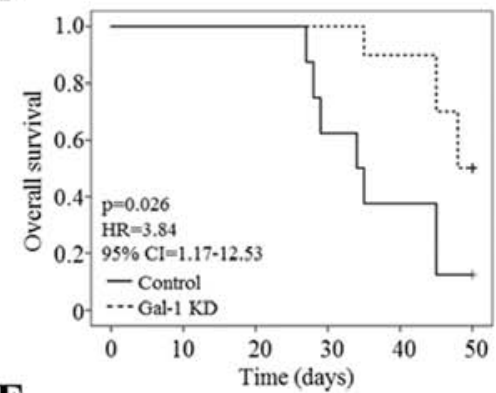

$\mathbf{E}$

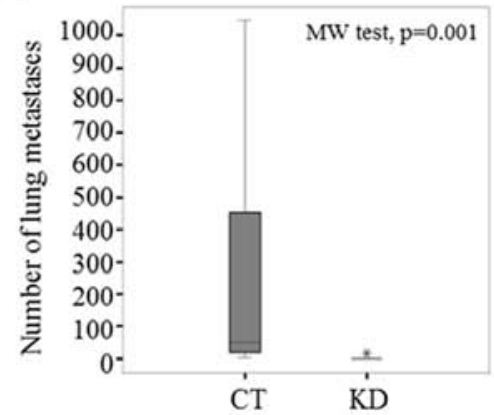

Figure 6. Orthotopic mouse model of anaplastic thyroid carcinoma. (A and B) The upper panel shows the representative axial sections of MRI recorded in nude mice at days 42 after $8505 \mathrm{C}$ control (CT) or knockdown (KD) tumor cell inoculation. The yellow arrows indicate the tumor localization. The middle and bottom panels represent histological examination of, respectively, tumor in animal thyroid and lung invasion at day 42 after $8505 \mathrm{C}$ control (A) or knockdown (B) tumor cell inoculation. The black arrow indicates lung metastasis in control mice. H\&E staining (magnification, $\mathrm{x} 200$ ). T, Tumor; Th, Thyroid gland. (C) Tumor volumes comparing control (CT) and galectin-1 knockdown (KD) mice at days 22 (left panel; p=0.0002, Mann-Whitney test) and 29 (right panel; $\mathrm{p}=0.0003$, Mann-Whitney test) after cancer cell inoculation. Data are presented as box plot where thick line is the median, bottom and top of the box are, respectively, the 1st and the 3rd quartiles, whiskers indicate the minimum and maximum non-outlier values, and * shows an extreme value. (D) Kaplan-Meier survival curves for control (CT) and galectin-1 knockdown (KD) mice (Cox regression, p=0.026). (E). Graph displaying the number of lung metastases in control (CT) and galectin-1 knockdown (KD) mice ( $\mathrm{p}=0.001$, Mann-Whitney test). Data are presented as box plot where thick line is the median, bottom and top of the box are, respectively, the 1st and the 3rd quartiles, whiskers indicate the minimum and maximum non-outlier values, and * shows an extreme value.

cell invasion compared to scrambled cells (Fig. 5B). Decrease in cell invasion was confirmed by counting the cell number that migrated through the membrane (Fig. 5C). Accordingly, the expression of the matrix metalloproteinase MMP9 in $8505 \mathrm{C}$ cells was significantly reduced as a result of galectin-1 knockdown (Fig. 5D). In contrast to our observations in TPC-1 cells, we did not observe any significant effect of galectin-1 depletion on $8505 \mathrm{C}$ cell migration (data not shown).

Effect of galectin-1 depletion on tumor growth in an orthotopic nude mouse model. A murine orthotopic model of human anaplastic thyroid carcinoma was developed to investigate the impact of galectin-1 depletion on tumor growth and metastatic dissemination in vivo. Control (CT, $\mathrm{n}=8)$ and galectin-1 knockdown (KD, n=10) 8505C anaplastic tumor cells were injected into the thyroids of nude mice. Primary tumor growth was followed in vivo using an MRI imaging system. In this model, tumor volume analysis revealed that all mice injected with $8505 \mathrm{C}$ control cells $(n=8)$ developed thyroid tumors within 22 days of injection (Fig. 6A top panel and $\mathrm{C}$ ). In contrast, mice injected with $8505 \mathrm{C}$ gal-1 KD cells showed slower $(n=4)$ or absent $(n=6)$ tumor development at days 22 and 29 after inoculation (Fig. 6B top panel and C). At day 42 post-injection, final tumor volumes were 53.1-1174.4 $\mathrm{mm}^{3}$ and $0-99.1 \mathrm{~mm}^{3}$ for control and galectin-1 knockdown mice, respectively. The Kaplan-Meier survival curve indicated that the downregulation of galectin-1 was significantly associated with better survival rate (univariate Cox regression, $\mathrm{p}=0.026$ ) (Fig. 6D). Histological analysis at day 50 of control tumors showed histopathological pattern of anaplastic thyroid 
carcinoma and revealed the presence of lung metastasis in all control mice (Fig. 6A middle and bottom panels). Of note, mice injected with galectin-1 KD cells showed small tumors at inoculation sites and minimal number of lung metastasis (Fig. 6B middle and bottom panels). The number of lung metastases (counted on five histological slides/mice) ranged from 4 to 1048 (median 50.5) and 0 to 14 (median 7) for control and galectin-1 knockdown mice, respectively ( $\mathrm{p}=0.001$, Mann-Whitney test) (Fig. 6E). Collectively, these data suggest that galectin-1 is required for tumor growth and lung metastasis development.

\section{Discussion}

Although conventional histology and FNA are considered as gold standards, the pathologists are confronted with difficulties in reaching an accurate differential diagnosis between benign and malignant thyroid nodules. To improve disease identification, immunohistochemical markers, such as cytokeratin-19 (CK19) and galectin-3, have been proposed and their efficiencies for thyroid cancer diagnosis have been evaluated. CK19 is the smallest member of cytokeratin family and belongs to the intermediate filaments. Several studies reported that CK19 expression is strong and diffuse in papillary carcinoma and absent or low in benign thyroid lesions $(8,9,15-17)$. Galectin-3, a structurally unique member of galectin family with an $\mathrm{N}$-terminal tail composed of nine collagen-like repeats and a peptide with sites for Ser phosphorylation (39), is anti-apoptotic, associated with the pathogenesis of well-differentiated thyroid carcinoma (7,10-14). However, these markers have shown some limitations because positivity was also reported in some benign cases (16-23). Mehrotra et al showed that galectin-3 was expressed in a large proportion of follicular adenomas, multinodular goiters and Hashimoto's thyroiditis (19). In the study of Mataraci et al, CK19 expression was found in adenomatous nodular hyperplasia and follicular adenoma (16). Thus, the current challenge is to find new immunohistochemical markers that might be more helpful to refine diagnosing thyroid cancer, to avoid unnecessary thyroidectomy. In this context, our data confirm previous studies preconizing the use of galectin-3 and CK19 as routine biomarkers to diagnose thyroid carcinomas $(40,41)$.

More importantly, it provides supplementary information on galectin-1 expression in both benign and malignant thyroid lesions. Our data showed that the expression of these markers is significantly higher in papillary carcinoma than in follicular adenoma. Herein, the galectin-1 displayed a high specificity of $97 \%$, suggesting that galectin-1 can be used in association with galectin-3 and CK19 as a complementary diagnostic tool to improve discrimination between benign and malignant thyroid neoplasms. Our observations validate and further support the potential value of galectin-1 in the diagnosis of well differentiated thyroid cancer as proposed by previous studies (33-35).

Since its discovery, altered galectin expression was frequently associated with many cellular processes and malignant transformation. In particular, galectin-1 was reported to contribute to pathogenesis, in a favorable or unfavorable manner depending on the cell type (32). Of relevance, a high serum level of galectin-1 occurs in patients diagnosed with a well-differentiated thyroid cancer (36). However, mechanisms by which galectin-1 can exert diverse effects in thyroid carcinogenesis and cancer progression remain still unknown. In the present study, we investigated the role of galectin-1 in the biology of thyroid carcinoma using shRNA strategy in two thyroid cancer cell lines. Our findings revealed that knockdown of galectin-1 resulted in the inhibition of TPC-1 cell migration, $8505 \mathrm{C}$ cell proliferation and invasion in vitro as well as in the remarkable decrease of tumor (and metastasis) development in vivo. This body of evidence suggests that galectin- 1 can be involved in the progression of thyroid carcinoma. Particularly, the impact of galectin-1 knockdown on invasion of anaplastic cancer cells (8505C) could probably be linked to the modulation of the matrix metalloprotein 9 (MMP9) expression. In fact, our results demonstrated that the down-regulation of galectin-1 led to the decrease of MMP9 expression. That the lectin is known as inducer of MMP9 and other pro-degradative/inflammatory effectors via NF- $\kappa \mathrm{B}(42)$ and also promotes breast cancer cell metastasis by upregulating MMP9 expression (43) flanks the assumption for a functional correlation. Due to the possible involvement of other proteins, the context dependence of these observations deserve attention (44).

Anaplastic thyroid carcinoma is one of the most aggressive human malignancies. Several studies had proposed orthotopic models of human thyroid cancer for testing novel therapeutic strategies (45-47). We evaluated the impact of galectin-1 depletion on tumor growth in an orthotopic nude mouse model of human anaplastic thyroid carcinoma. Our in vivo experiments revealed reduced or lack of tumor growth and lung metastasis, as well as prolonged survival, in galectin-1 KD mice compared to control mice. These findings support that galectin-1 directly affects thyroid cancer development and may represent a suitable target for intervention in anaplastic thyroid carcinoma.

In summary, our data showed that galectin-1 is a good immunohistochemical marker that could meaningfully complement information by monitoring galectin-3 and cytokeratin-19 in the quest to discriminate benign thyroid nodules from malignant tumors. Its observed involvement in cell proliferation, migration and invasion in vitro, as well as in tumor growth in vivo also support that galectin-1 plays functional roles in tumor progression and metastasis formation. Impact on NF- $\kappa \mathrm{B}$ or hedgehog signaling or Rho GTPases can underlie these activities $(32,48,49)$, targeting counterreceptor cross-linking offering an opportunity to block these protumoral routes (50). In aggregate, these data indicate an association of galectin-1 and -3 expression with likely functional cooperation, encouraging to further study the galectin network.

\section{Acknowledgements}

A.W. was granted by the Télévie (F. R. S.-FNRS, Belgian National Fund for Scientific Research, 22877711). The study received financial support from the 'Fonds pour l'Action de Recherche Concertée' (ARC-14/19 UMONS 3) (Belgium). The Center for Microscopy and Molecular Imaging (CMMI) is supported by the European Regional Development Fund and Wallonia. We thank Benoît Bauduin for his help in MRI (acquisition and processing of images). 


\section{References}

1. Pellegriti G, Frasca F, Regalbuto C, Squatrito S and Vigneri R: Worldwide increasing incidence of thyroid cancer: Update on epidemiology and risk factors. J Cancer Epidemiol 2013: 965212, 2013.

2. Goyal N, Setabutr D, Abdulghani J and Goldenberg D: Molecular and genetic markers of follicular-cell thyroid cancer: Etiology and diagnostic and therapeutic opportunities. Adv Exp Med Biol 779: 309-326, 2013.

3. Nikiforov YE: Molecular diagnostics of thyroid tumors. Arch Pathol Lab Med 135: 569-577, 2011.

4. Grogan RH, Mitmaker EJ and Clark OH: The evolution of biomarkers in thyroid cancer-from mass screening to a personalized biosignature. Cancers (Basel) 2: 885-912, 2010.

5. Cabanillas ME, Patel A, Danysh BP, Dadu R, Kopetz S and Falchook G: BRAF inhibitors: Experience in thyroid cancer and general review of toxicity. Horm Cancer 6: 21-36, 2015.

6. Kim KB, Cabanillas ME, Lazar AJ, Williams MD, Sanders DL, Ilagan JL, Nolop K, Lee RJ and Sherman SI: Clinical responses to vemurafenib in patients with metastatic papillary thyroid cancer harboring BRAF(V600E) mutation. Thyroid 23: 1277-1283, 2013.

7. Liu Z, Li X, Shi L, Maimaiti Y, Chen T, Li Z, Wang S, Xiong Y, Guo H, He W, et al: Cytokeratin 19, thyroperoxidase, HBME-1 and galectin-3 in evaluation of aggressive behavior of papillary thyroid carcinoma. Int J Clin Exp Med 7: 2304-2308, 2014

8. Flanagan JN, Pineda P, Knapp PE, De Las Morenas A, Lee SL and Braverman LE: Expression of cytokeratin 19 in the diagnosis of thyroid papillary carcinoma by quantitative polymerase chain reaction. Endocr Pract 14: 168-174, 2008.

9. Krzeslak A, Gaj Z, Pomorski L and Lipinska A: Expression of cytokeratin 19 in the cytosolic fraction of thyroid lesions: ELISA and western blot analysis. Mol Med Rep 1: 565-569, 2008.

10. Sumana BS, Shashidhar S and Shivarudrappa AS: Galectin-3 immunohistochemical expression in thyroid neoplasms. J Clin Diagn Res 9: EC07-EC11, 2015.

11. Bartolazzi A, Gasbarri A, Papotti M, Bussolati G, Lucante T, Khan A, Inohara H, Marandino F, Orlandi F, Nardi F, et al; Thyroid Cancer Study Group: Application of an immunodiagnostic method for improving preoperative diagnosis of nodular thyroid lesions. Lancet 357: 1644-1650, 2001.

12. Inohara H, Honjo Y, Yoshii T, Akahani S, Yoshida J, Hattori K Okamoto S, Sawada T, Raz A and Kubo T: Expression of galectin-3 in fine-needle aspirates as a diagnostic marker differentiating benign from malignant thyroid neoplasms. Cancer 85 2475-2484, 1999.

13. Gasbarri A, Martegani MP, Del Prete F, Lucante T, Natali PG and Bartolazzi A: Galectin-3 and CD44v6 isoforms in the preoperative evaluation of thyroid nodules. J Clin Oncol 17: 3494-3502, 1999.

14. Carpi A, Rossi G, Coscio GD, Iervasi G, Nicolini A, Carpi F, Mechanick JI and Bartolazzi A: Galectin-3 detection on largeneedle aspiration biopsy improves preoperative selection of thyroid nodules: A prospective cohort study. Ann Med 42: 70-78, 2010.

15. Liu Z, Yu P, Xiong Y, Zeng W, Li X, Maiaiti Y, Wang S, Song H, Shi L, Liu C, et al: Significance of CK19, TPO, and HBME-1 expression for diagnosis of papillary thyroid carcinoma. Int J Clin Exp Med 8: 4369-4374, 2015.

16. Mataraci EA, Ozgüven BY and Kabukçuoglu F: Expression of cytokeratin 19, HBME-1 and galectin-3 in neoplastic and nonneoplastic thyroid lesions. Pol J Pathol 63: 58-64, 2012.

17. Schmitt AC, Cohen C and Siddiqui MT: Paired box gene 8 , HBME-1, and cytokeratin 19 expression in preoperative fineneedle aspiration of papillary thyroid carcinoma: Diagnostic utility. Cancer Cytopathol 118: 196-202, 2010.

18. Niedziela M, Maceluch J and Korman E: Galectin-3 is not an universal marker of malignancy in thyroid nodular disease in children and adolescents. J Clin Endocrinol Metab 87: 4411-4415, 2002.

19. Mehrotra P, Okpokam A, Bouhaidar R, Johnson SJ, Wilson JA, Davies BR and Lennard TWJ: Galectin-3 does not reliably distinguish benign from malignant thyroid neoplasms. Histopathology 45: 493-500, 2004.

20. Mills LJ, Poller DN and Yiangou C: Galectin-3 is not useful in thyroid FNA. Cytopathology 16: 132-138, 2005.
21. Park YJ, Kwak SH, Kim DC, Kim H, Choe G, Park DJ, Jang HC, Park SH, Cho BY and Park SY: Diagnostic value of galectin-3, HBME-1, cytokeratin 19, high molecular weight cytokeratin, cyclin D1 and p27(kip1) in the differential diagnosis of thyroid nodules. J Korean Med Sci 22: 621-628, 2007.

22. Zhu X, Sun T, Lu H, Zhou X, Lu Y, Cai X and Zhu X: Diagnostic significance of CK19, RET, galectin-3 and HBME-1 expression for papillary thyroid carcinoma. J Clin Pathol 63: 786-789, 2010.

23. Barroeta JE, Baloch ZW, Lal P, Pasha TL, Zhang PJ and LiVolsi VA: Diagnostic value of differential expression of CK19, Galectin-3, HBME-1, ERK, RET, and p16 in benign and malignant follicular-derived lesions of the thyroid: An immunohistochemical tissue microarray analysis. Endocr Pathol 17: 225-234, 2006

24. Hirabayashi J (ed): Recent topics on galectins. Trends Glycosci Glycotechnol 9: 1-180, 1997.

25. Kaltner $\mathrm{H}$ and Gabius $\mathrm{HJ}$ : A toolbox of lectins for translating the sugar code: The galectin network in phylogenesis and tumors. Histol Histopathol 27: 397-416, 2012.

26. Cludts S, Decaestecker C, Mahillon V, Chevalier D, Kaltner H, André S, Remmelink M, Leroy X, Gabius HJ and Saussez S: Galectin-8 up-regulation during hypopharyngeal and laryngeal tumor progression and comparison with galectin-1, -3 and -7 . Anticancer Res 29: 4933-4940, 2009.

27. Remmelink M, de Leval L, Decaestecker C, Duray A, Crompot E, Sirtaine N, André S, Kaltner H, Leroy X, Gabius HJ, et al: Quantitative immunohistochemical fingerprinting of adhesion/growth-regulatory galectins in salivary gland tumours: Divergent profiles with diagnostic potential. Histopathology 58 543-556, 2011.

28. Dawson H, André S, Karamitopoulou E, Zlobec I and Gabius HJ: The growing galectin network in colon cancer and clinical relevance of cytoplasmic galectin-3 reactivity. Anticancer Res 33: 3053-3059, 2013.

29. Toegel S, Bieder D, André S, Kayser K, Walzer SM, Hobusch G, Windhager $\mathrm{R}$ and Gabius HJ: Human osteoarthritic knee cartilage: Fingerprinting of adhesion/growth-regulatory galectins in vitro and in situ indicates differential upregulation in severe degeneration. Histochem Cell Biol 142: 373-388, 2014.

30. Saussez S, Decaestecker C, Cludts S, Ernoux P, Chevalier D, Smetana K Jr, André S, Leroy X and Gabius HJ: Adhesion/ growth-regulatory tissue lectin galectin-1 in relation to angiogenesis/lymphocyte infiltration and prognostic relevance of stromal up-regulation in laryngeal carcinomas. Anticancer Res 29: 59-65, 2009.

31. Amano M, Eriksson H, Manning JC, Detjen KM, André S, Nishimura S, Lehtiö J and Gabius HJ: Tumour suppressor p16(INK4a) - anoikis-favouring decrease in N/O-glycan/cell surface sialylation by down-regulation of enzymes in sialic acid biosynthesis in tandem in a pancreatic carcinoma model. FEBS J 279: 4062-4080, 2012

32. Smetana K Jr, André S, Kaltner H, Kopitz J and Gabius HJ: Context-dependent multifunctionality of galectin-1: A challenge for defining the lectin as therapeutic target. Expert Opin Ther Targets 17: 379-392, 2013.

33. Chiariotti L, Berlingieri MT, Battaglia C, Benvenuto G, Martelli ML, Salvatore P, Chiappetta G, Bruni CB and Fusco A: Expression of galectin-1 in normal human thyroid gland and in differentiated and poorly differentiated thyroid tumors. Int J Cancer 64: 171-175, 1995.

34. Xu XC, el-Naggar AK and Lotan R: Differential expression of galectin-1 and galectin-3 in thyroid tumors. Potential diagnostic implications. Am J Pathol 147: 815-822, 1995.

35. Salajegheh A, Dolan-Evans E, Sullivan E, Irani S, Rahman MA, Vosgha H, Gopalan V, Smith RA and Lam AK: The expression profiles of the galectin gene family in primary and metastatic papillary thyroid carcinoma with particular emphasis on galectin-1 and galectin-3 expression. Exp Mol Pathol 96: 212-218, 2014.

36. Saussez S, Glinoer D, Chantrain G, Pattou F, Carnaille B, André S, Gabius HJ and Laurent G: Serum galectin-1 and galectin-3 levels in benign and malignant nodular thyroid disease. Thyroid 18: 705-712, 2008

37. Kaltner H, Seyrek K, Heck A, Sinowatz F and Gabius HJ: Galectin-1 and galectin-3 in fetal development of bovine respiratory and digestive tracts. Comparison of cell type-specific expression profiles and subcellular localization. Cell Tissue Res 307: 35-46, 2002. 
38. Livak KJ and Schmittgen TD: Analysis of relative gene expression data using real-time quantitative PCR and the 2(-Delta Delta C(T)) method. Methods 25: 402-408, 2001.

39. Kopitz J, Vértesy S, André S, Fiedler S, Schnölzer M and Gabius HJ: Human chimera-type galectin-3: Defining the critical tail length for high-affinity glycoprotein/cell surface binding and functional competition with galectin-1 in neuroblastoma cell growth regulation. Biochimie 104: 90-99, 2014.

40. de Matos LL, Del Giglio AB, Matsubayashi CO, de Lima Farah M, Del Giglio A and da Silva Pinhal MA: Expression of CK-19, galectin-3 and HBME-1 in the differentiation of thyroid lesions: Systematic review and diagnostic meta-analysis. Diagn Pathol 7: 97, 2012.

41. Dunđerović D, Lipkovski JM, Boričic I, Soldatović I, Božic V, Cvejić D and Tatić S: Defining the value of CD56, CK19, Galectin 3 and HBME-1 in diagnosis of follicular cell derived lesions of thyroid with systematic review of literature. Diagn Pathol 10: 196, 2015.

42. Toegel S, Weinmann D, André S, Walzer SM, Bilban M, Schmidt S, Chiari C, Windhager R, Krall C, Bennani-Baiti IM, et al: Galectin-1 couples glycobiology to inflammation in osteoarthritis through the activation of an NF- $\mathrm{kB}$-regulated gene network. J Immunol 196: 1910-1921, 2016.

43. Zhu X, Wang K, Zhang K, Xu F, Yin Y, Zhu L and Zhou F: Galectin-1 knockdown in carcinoma-associated fibroblasts inhibits migration and invasion of human MDA-MB-231 breast cancer cells by modulating MMP-9 expression. Acta Biochim Biophys Sin (Shanghai) 48: 462-467, 2016.

44. Saussez S, Cludts S, Capouillez A, Mortuaire G, Smetana K Jr, Kaltner H, André S, Leroy X, Gabius HJ and Decaestecker C: Identification of matrix metalloproteinase-9 as an independent prognostic marker in laryngeal and hypopharyngeal cancer with opposite correlations to adhesion/growth-regulatory galectins-1 and -7. Int J Oncol 34: 433-439, 2009.
45. Nucera C, Nehs MA, Mekel M, Zhang X, Hodin R, Lawler J, Nose V and Parangi S: A novel orthotopic mouse model of human anaplastic thyroid carcinoma. Thyroid 19: 1077-1084, 2009.

46. Sewell W, Reeb A and Lin RY: An orthotopic mouse model of anaplastic thyroid carcinoma. J Vis Exp 74: 2013 doi: $10.3791 / 50097$.

47. Antonello ZA and Nucera C: Orthotopic mouse models for the preclinical and translational study of targeted therapies against metastatic human thyroid carcinoma with BRAF(V600E) or wild-type BRAF. Oncogene 33: 5397-5404, 2014.

48. Camby I, Belot N, Lefranc F, Sadeghi N, de Launoit Y, Kaltner H, Musette S, Darro F, Danguy A, Salmon I, et al: Galectin-1 modulates human glioblastoma cell migration into the brain through modifications to the actin cytoskeleton and levels of expression of small GTPases. J Neuropathol Exp Neurol 61: 585-596, 2002.

49. Martínez-Bosch N, Fernández-Barrena MG, Moreno M, OrtizZapater E, Munné-Collado J, Iglesias M, André S, Gabius HJ, Hwang RF, Poirier F, et al: Galectin-1 drives pancreatic carcinogenesis through stroma remodeling and Hedgehog signaling activation. Cancer Res 74: 3512-3524, 2014.

50. Solís D, Bovin NV, Davis AP, Jiménez-Barbero J, Romero A, Roy R, Smetana K Jr and Gabius HJ: A guide into glycosciences: How chemistry, biochemistry and biology cooperate to crack the sugar code. Biochim Biophys Acta 1850: 186-235, 2015. 